\title{
Health Status of Cycle Rickshaw Pullers in Allahabad (India)
}

\author{
U. Minhas', D. Kumar' , A. Ali' ${ }^{1}$, D. Yadav' ${ }^{1}$, R. Kesarwani', S. P. Gupta ${ }^{1}$ and R. Kumar²* \\ 'Department of Biochemistry, University of Allahabad, Allahabad - 211002, Uttar Pradesh, India \\ 2Wazir Ram Singh Government College Dehri-176022, District Kangra, Himachal Pradesh, India; \\ rbotany@gmail.com
}

\begin{abstract}
Occupation is one of the most important extrinsic factors which have the major impact on health. Pedalling the tricycle rickshaw is a most stressful job. Rickshaw Pullers are extensively exposed to the air pollutants in conjunction with strenuous exercise. In the present study demographic details along with nutritional status, hygiene status and morbid conditions were obtained from fifty Rickshaw Pullers (RPs) in Allahabad.
\end{abstract}

Keywords: Allahabad, Cycle Rickshaw Pullers, Health

\section{Introduction}

The Rickshaw Pullers act as the main mode of human powered transportation for short distances in the urban areas. In a country like India air pollution in urban cities is on rise and transportation system contributes to a major extent. Cycle rickshaws are the most environmental friendly and cheapest mode of transportation and large number of people in urban cities uses it for commutation. Considering cycle rickshaw pulling as a highly strenuous occupation, most of the developing countries are discouraging it, despite the fact that it is pro-environment mode of transportation (Gadepalli, 2006²).

Rickshaw Pullers are a part of $90 \%$ workforce which comes under unorganised sector. In India, about 0.86 million people are engaged in pulling cycle rickshaws as occupation (Pradhan, 20104). Most RPs are rural migrants which due to lack of opportunities and poverty come to urban areas for work to support their families back in their villages. However, this occupation doesn't help them much. High level of physical activity, lack of housing facility, clean water to drink, medical facilities along with insensitive attitude of people from middle and upper class, municipal bodies and police towards them make their lives hell.

Occupation is one of the most important extrinsic factors which have the major impact on health. Pedalling the tricycle rickshaw is a most stressful job. It requires extensive muscle force and is linked with heavy work load, which increases in summer because of high temperature and humidity (Azer et al., 1972' ; Hancock et al., 2003³). In Allahabad, Uttar Pradesh, mean air temperature during summer (April to June) ranges between $40-45^{\circ} \mathrm{C}$. Rickshaw pulling has been reported to be positively associated with high cardiovascular load (Sahu et al., 20135).

The strenuous work under the harsh urban environment, competition from other modes of public transport, lack of proper diet and rest, indulgence in harmful substances with a belief of physical relaxation and recreation etc. pose as health risks to this section of the population. Still not much has been done for the upliftment of health of rickshaw pullers. The present study was specifically designed to analyse the clinical health status of Rickshaw Pullers in Allahabad region.

\section{Methodology}

The study was conducted in months of March-April. Total of 50 Rickshaw Pullers in Allahabad were interviewed and their blood was collected for the assessment of their clinical health. Informed consent was obtained from all volunteers. The study was conducted in accordance with the ethics committee of the study centre. The volunteers were briefed in detail on the objectives of the study. For interview based health assessment, the demographic details along with nutritional status, hygiene status and morbid conditions were obtained. Their body weight and height was taken to calculate their BMI. For blood chemistry $2 \mathrm{ml}$ of blood was obtained and random blood glucose, haemoglobin levels and total blood count were carried

${ }^{*}$ Author for correspondence 
out. Random blood glucose was done using a glucometer; total blood count was done using a $\mathrm{CBC}$ machine. Statistical analyses were performed using a Graph pad Prism 7 computer software package and all values were expressed as mean \pm Standard Deviation (SD). Proportions were analysed by using Chisquare test. $\mathrm{p}<0.05$ was taken as significant difference.

\section{Results}

The demographic details of Rickshaw Pullers (RPs) in Allahabad have been shown in (Table 1). It was revealed that $70 \%$ RPs were totally illiterate whereas $20 \%$ had the primary education and only $10 \%$ were high school pass. Education has been linked with poverty. Attainment of education should reduce poverty. However, poor education system especially in rural India has led to poor achievement in this ground.

Further, $72 \%$ RPs had the earnings less than 200 rupees per day. During the interview it was revealed that $80 \%$ of the rickshaws were rented and the daily rent was from rupees 100 to 150 per day. Therefore, their actual income should be much less than that. $90 \%$ of the RPs involved in the study was in this occupation for more than five years. $90 \%$ of the RPs admitted that their rickshaw was registered. $86 \%$ was married where as $4 \%$ were divorced/separated and $10 \%$ were unmarried. However, all of them had family members dependent on them. Further, $60 \%$ were working more than eight hours a day.

Nutritional status of RPs as depicted in (Table 2) shows the data about the type of diet (vegetarian or non-vegetarian), their eating pattern, substance abuse and their Body Mass Index. $70 \%$ of the RPs was non-vegetarian (not on the daily

Table 1. Demographic details of RPs in Allahabad

\begin{tabular}{|c|c|c|c|}
\hline \multicolumn{2}{|c|}{ Demographic details } & Number & Proportion (\%) \\
\hline \multirow{3}{*}{$\begin{array}{l}\text { Educational } \\
\text { Qualification }\end{array}$} & Nil & 35 & 70 \\
\hline & Primary & 10 & 20 \\
\hline & $10^{\text {th }}$ & 5 & 10 \\
\hline \multirow{2}{*}{$\begin{array}{l}\text { Earnings per } \\
\text { day }\end{array}$} & Less than 200/- & 36 & 72 \\
\hline & Less than $500 /-$ & 14 & 28 \\
\hline \multirow{2}{*}{$\begin{array}{l}\text { Ownership of } \\
\text { Rickshaw }\end{array}$} & Own & 10 & 20 \\
\hline & Rented & 40 & 80 \\
\hline \multirow{2}{*}{$\begin{array}{l}\text { Duration of } \\
\text { service }\end{array}$} & $<5$ yrs & 5 & 10 \\
\hline & $>5 \mathrm{yrs}$ & 45 & 90 \\
\hline \multirow{2}{*}{$\begin{array}{l}\text { Registry of } \\
\text { rickshaw }\end{array}$} & Yes & 45 & 90 \\
\hline & No & 5 & 10 \\
\hline \multirow[t]{3}{*}{ Marital Status } & Married & 43 & 86 \\
\hline & Unmarried & 5 & 10 \\
\hline & Divorced & 2 & 4 \\
\hline \multirow{2}{*}{$\begin{array}{l}\text { Working Hour } \\
\text { Per Day }\end{array}$} & Less than 8 hrs & 20 & 40 \\
\hline & more than 8 hrs & 30 & 60 \\
\hline
\end{tabular}

Table 2. Nutritional status of RPs in Allahabad

\begin{tabular}{|l|l|c|c|}
\hline \multicolumn{2}{|l|}{ Nutritional status } & Number & Proportion (\%) \\
\hline \multirow{3}{*}{ Type of diet } & Vegetarian & 15 & $\mathbf{3 0}$ \\
\cline { 2 - 4 } & Non-Vegetarian & 35 & $\mathbf{7 0}$ \\
\hline \multirow{2}{*}{$\begin{array}{l}\text { Eating } \\
\text { pattern }\end{array}$} & Regular & 4 & $\mathbf{8}$ \\
\cline { 2 - 4 } & Irregular & 46 & $\mathbf{9 2}$ \\
\hline \multirow{2}{*}{$\begin{array}{l}\text { Substance } \\
\text { abuse }\end{array}$} & Present & 45 & 90 \\
\cline { 2 - 4 } & Nil & 5 & $\mathbf{1 0}$ \\
\hline \multirow{3}{*}{ BMI } & less than 18.5 & 35 & $\mathbf{7 0}$ \\
\cline { 2 - 4 } & $18.5-25$ & 15 & $\mathbf{3 0}$ \\
\cline { 2 - 4 } & $25-30$ & 0 & $\mathbf{0}$ \\
\cline { 2 - 4 } & above 30 & 0 & $\mathbf{0}$ \\
\hline
\end{tabular}

Table 3. Morbid conditions in RPs in Allahabad

\begin{tabular}{|c|c|c|c|}
\hline \multicolumn{2}{|c|}{ Morbid condition } & No. & Proportion (\%) \\
\hline \multicolumn{2}{|c|}{ Musculoskeletal } & 34 & 68 \\
\hline \multicolumn{2}{|c|}{ Respiratory } & 7 & 14 \\
\hline \multicolumn{2}{|c|}{ Gastrointestinal } & 13 & 26 \\
\hline \multicolumn{2}{|c|}{ Genitourinary } & 9 & 18 \\
\hline \multicolumn{2}{|c|}{ Skin } & 4 & 8 \\
\hline \multicolumn{2}{|c|}{ Eye } & 5 & 10 \\
\hline \multicolumn{2}{|c|}{ Dental } & 30 & 60 \\
\hline \multirow[t]{3}{*}{$\mathrm{BP}$} & Normal: $120 / 80$ - 140/90 & 13 & 26 \\
\hline & High: Above 140/90 & Nil & $\mathbf{0}$ \\
\hline & Low below: 120/80 & 37 & 74 \\
\hline
\end{tabular}

basis). $92 \%$ said that their eating pattern was irregular. Their two major meals were in the morning and night. During the day they eat mainly street food and some people do not eat at all. 90\% of the RPs disclosed about having beedi, gutka, zarda, tobacco, alcohol and other drugs. Body Mass Index of $70 \%$ Rickshaw Pullers was found to be less than 18.5 which mean they were underweight. These hapless Rickshaw Pullers had a poor and frail appearance.

Morbid conditions as shown in (Table 3) illustrate that major morbid conditions as reported by RPs were musculoskeletal problems (68\%) along with low BP (74\%) and dental problems $(60 \%)$. Rest of the conditions reported were less in percentage. Relationship of morbid conditions with years of service, earnings per day, working hours per day and BMI was analysed by chi-square test. Musculoskeletal conditions were found to be significantly related to years of service, working hours/day and substance abuse as well as BMI. The proportion graphs are depicted in (Figure 1). Other morbid conditions were not found to be significantly related to any of the demographic and nutritional status. These findings suggest that chronic physical stresses along with nutritional insufficiency are main factors 
musculoskeletal condition with years of service

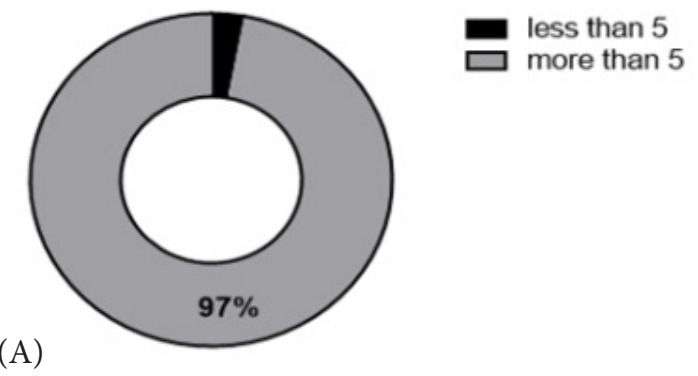

Total $=34$

\section{Prospective (musculoskelatal condition and working hours)}

(B)

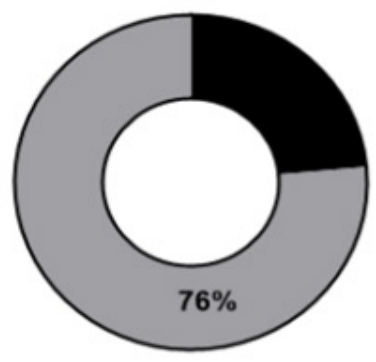

Total $=34$
Prospective (musculoskelatal condition and substance abuse)

(C)

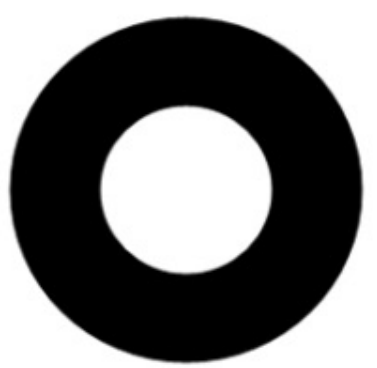

Total $=34$
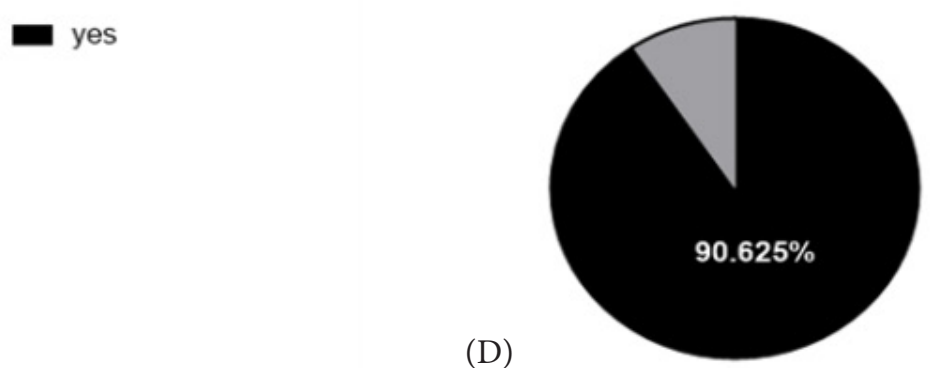

Total $=32$

(D)

Prospective (musculoskelatal condition and BMI)

Figure 1. Pie diagrams showing relationship of Muculoskeletal condition with years of service. (A). working hours/day (B). substance abuse (C). and BMI (D). Data is shown as proportions, $\mathrm{n}=50$.

Table 4. Levels of glucose and complete blood count in whole blood of RPs. $\mathrm{N}=6$, values are expressed as mean \pm SD

\begin{tabular}{|c|c|c|c|c|c|c|c|c|}
\hline & Glucose (random) & $\mathrm{Hgb}$ & WBC & Lym & Mono & Gran & $\mathrm{RBC}$ & Platelet \\
\hline Normal range & $\begin{array}{l}80-140 \\
\mathrm{mg} / \mathrm{dl}\end{array}$ & $\begin{array}{c}14-17 \\
\mathrm{~g} / \mathrm{dl}\end{array}$ & $\begin{array}{c}4.0-12.0 \mathrm{x} \\
10^{3} / \mu \mathrm{l}\end{array}$ & $\begin{array}{c}1.0-5.0 \mathrm{x} \\
10^{3} / \mu \mathrm{l} \\
\end{array}$ & $\begin{array}{c}0.1-1.0 \mathrm{x} \\
10^{3} / \mu \mathrm{l}\end{array}$ & $\begin{array}{c}2.0-8.0 \mathrm{x} \\
10^{3} / \mu \mathrm{l}\end{array}$ & $\begin{array}{c}4.3-6.2 \mathrm{x} \\
10^{6} / \mu \mathrm{l}\end{array}$ & $\begin{array}{c}150-400 \mathrm{x} \\
10^{3} / \mu \mathrm{l}\end{array}$ \\
\hline $\mathrm{N}=50 \mathrm{RPs}$ & $93 \pm 14$ & $11.23 \pm 1.2$ & $4.6 \pm 1.5$ & $3.5 \pm 3.31$ & $2.6 \pm 2.24$ & $3.0 \pm 2.7$ & $4.4 \pm 1.0$ & $162.1 \pm 48.73$ \\
\hline
\end{tabular}

responsible for development of musculoskeletal conditions in these individuals overtime.

Nutritional status is strongly associated with the level of health and quality of life of the population. Malnutrition is a common complication in RPs due to poverty. Low BMI is associated with malnutrition and high metabolic rate. Malnutrition is positively correlated with poverty, anorexia, bulimia or malabsorption. Body Mass Index was measured in RPs. 64\% RPs were found to be under weight clearly suggesting poor nutritional status in these individuals (Table 2). Additionally, 74\% of RPs had lower blood pressure reflecting malnutrition which is common condition in RPs. Malnutrition is one of main causes of low BP.

Blood glucose and complete blood count of six RPs are shown in (Table 4). Haemoglobin levels were found to be quite low indicating anaemia which further reflects malnutrition in these subjects.

\section{Discussion}

Impact of occupation on health is undeniable. The hand pulled rickshaws have already been banned in India. Cycle rickshaw pulling is also being discouraged by government despite the fact that it is the most environment friendly mode of transportation. In the present study, it was revealed that majority of RPs were poor and illiterate having daily earnings approximately around Rs. 100/-. The nutritional status also was grim with majority of RPs having irregular eating habits along with substance abuse and low BMI. Majority of RPs were found to be affected by musculoskeletal conditions such as joint pain, body pain. In order to get relief from joint and body pain after a hard long day, they get into substance abuse. The dental problems which they have reflect their poor hygiene habits along with substance abuse such as smoking and chewing paan and gutka. 


\section{Conclusions}

The cycle rickshaws are the main mode of transportation for short distances in the urban areas. The strenuous work under the harsh urban environment, competition from other modes of public transport, lack of proper diet and rest, indulgence in harmful substances with a belief of physical relaxation and recreation etc. pose as health risks to this section of the population. Still not much has been done for the up-liftment of health of rickshaw pullers. The present study portrays that chronic physical stresses along with nutritional insufficiency are main factors responsible for development of musculoskeletal conditions in these individuals overtime. Considering the fact that cycle rickshaws are environment friendly mode of transport and rickshaw pulling is a major way of livelihood for many poor people in the country, the government need to pay attention on this field. This study is expected to give clear scenario of above mentioned health parameters among these subjects in this part of the country. The results may further strengthen the requirement for action to be taken for the upliftment of health in Rickshaw Pullers in this region.

\section{Acknowledgements}

Authors are thankful to UGC for proving start-up grant, Department of Science and Technology for DST-SAP grant and Head of the department of Biochemistry, University of Allahabad for providing necessary lab facilities for the present study.

\section{References}

1. Azer NZ, McNall PE, Leung HC. Effects of heat stress on performance. Ergonomics.1972; 15(6):681-91. PMid: 4652866. https://doi.org/10.1080/00140137208924468

2. Gadepalli S. Rickshaws in the new millennium Appropriate Technology. ProQuest Central. 2006; 33:4.

3. Hancock PA, Vasmatzidis I. Effects of heat stress on cognitive performance: The current state of knowledge. Int J Hyperthermia. 2003; 19(3):355-72. PMid: 12745975. https://doi .org/10.1080/0265673021000054630

4. Pradhan C. Anthropometric characteristics of Indian cycle Rickshaw Pullers. Journal of Human Ergology. 2010; 39(2): 79-88.

5. Sahu S, Maity SG, Moitra S, Sett M, Haldar P. Cardiovascular load during summer work of two age groups of van-Rickshaw Pullers in West Bengal, India. Int J Occup Saf Ergon. 2013; 19(4):657-65. PMid: 24321644. https://doi.org/10.1080/10803548.2013.11077019 